\title{
LA LABOR POLÍTICO-SOCIAL DE SECCIÓN FEMENINA DURANTE EL FRANQUISMO EN JAÉN
}

\author{
The political-social labor of Female Section during francoist in Jaen
}

\author{
Ana Belén Gómez Fernández \\ Universidad de Jaén \\ abgomez@ujaen.es
}

Fecha de recepción: 16-II-2012

Fecha de aceptación: 5-III-2012

Resumen: En el presente artículo tratamos de abordar un estudio sobre el campo de acción de Sección Femenina, teniendo como marco de análisis la provincia de Jaén. Una provincia caracterizada por una importante presencia del mundo rural, ámbito donde Sección Femenina desplegó una importante labor político-social sobre las mujeres, destacando su papel tradicional dentro del ámbito privado y en el desarrollo de la economía rural. Sin embargo, en los últimos años del franquismo, Sección Femenina intentó borrar ese pasado antifeminista ayudando a la mujer a aumentar su presencia en la esfera laboral y en el espacio público.

Palabras clave: Sección Femenina, Jaén, asistencia social, adoctrinamiento político, franquismo.

AвSTRACT: In this article I endeavour to analyse on the field of action of Feminine Section, taking the province of Jaen as a frame of analysis. A province characterized by an important presence of the rural world, area where Female Section opened an important political - social labor on the women, emphasizing his traditional paper inside the private area and in the development of the rural economy. Nevertheless, in the last years of the Franco's regime, Female Section there tried to erase this past antifeminist helped the woman to increasing his presence in the labor sphere and in the public space.

Keywords: Female Section, Jaen, social assistance, political indoctrination, francoist. 


\section{INTRODUCCIÓN}

La incorporación de los estudios de género en la historiografía actual resulta indispensable, sobre todo a partir de la abundante producción historiográfica que se basa en el protagonismo de la mujer. Para ello es básico analizar los mecanismos de subalternidad hacia la mujer, al igual que sus diversas estrategias y capacidad de reacción de las mismas. El marco histórico de la dictadura franquista constituye un caldo de cultivo excepcional que permite el análisis de las relaciones de poder desde un enfoque de género. El franquismo construyó su propio modelo de mujer entre la influencia tradicional y conservadora del catolicismo imperante, siendo uno de los pilares fundamentales de legitimación, y el discurso defendido por el fascismo frente a los cambios que comenzaba a reclamar el feminismo que surgía en los años treinta.

En este trabajo pretendemos realizar un análisis acerca de la dimensión de la acción social y política que Sección Femenina realizó durante el franquismo. Para ello se ha tomado como laboratorio de análisis la provincia de Jaén caracterizada por una importante presencia del mundo rural. Una sociedad básica agraria donde Sección Femenina desplegaría sus alas de influencia a lo largo de casi cuarenta años. Si durante los primeros años de la dictadura el discurso se dirigía a la situación de la mujer en la esfera privada, en los años del desarrollismo el discurso se orienta hacia una mayor participación en el espacio público, teniendo en cuenta que:

en toda sociedad la producción del discurso está a la vez. controlada, seleccionada y redistribuida por cierto numero de procedimientos que tiene por función conjurar los poderes y peligros, dominar el acontecimiento aleatorio y esquivar su pesada y temible materialidad.

Teniendo en cuenta lo anterior, la explicación de la labor de Sección Femenina en el adoctrinamiento de la mujer no puede hacerse sin tener en cuenta una serie de cuestiones y elementos que se analizarán en las siguientes páginas. En este sentido, no puede obviarse el papel que la mujer desempeñó en las relaciones sociales de la vida cotidiana durante el régimen franquista. Un papel marcado por la dependencia de viejas ideas patriarcales, así como por elementos renovadores, inspirados en los fascismos europeos ${ }^{2}$. Junto a

1 Michel FOCAULT, El orden del discurso, Barcelona, Tusquets, 2005, p. 14.

2 Rosario SÁNCHEZ LÓPEZ, Mujer española, una sombra de destino en lo universal. Trayectoria 
ello analizaremos el gran interés que tuvo Sección Femenina en formar a la mujer tanto en aspectos educativos como profesionales y especialmente las mejoras que se debían llevar a cabo en el medio rural, creando para ello diversos establecimientos o centros de formación repartidos por toda la provincia. Pero, sin duda, esta participación de mujeres en diferentes cursos, escuelas de formación se iría combinando con su implicación en un universo más amplio, es decir, su presencia en la esfera pública, esforzándose por la introducción cambios políticos y sociales en amplios sectores de la población femenina.

\section{El PAPEL DE LA MUJER EN EL FRANQUismo}

Según Zimbalist:

el estatus de las mujeres será inferior en aquellas sociedades en las que exista una fuerte diferenciación entre los terrenos de actividad doméstica y pública, y en aquellas en que las mujeres estén aisladas unas de otras y colocadas bajo la autoridad de un solo hombre en la casa ${ }^{3}$.

De este modo, podríamos encuadrar al franquismo dentro de esta órbita, donde la actividad doméstica de la mujer es entendida como su actividad natural, que a su vez carece de iniciativa propia, depositada en la figura masculina. El régimen franquista se alimentó de los discursos institucionales para desarrollar un sistema patriarcal agresivo, que mantuviese una doble dominación sobre las mujeres. En palabras de Di Febo:

la reactualización de lo femenino tradicional no responde solamente a la necesidad de restaurar un antiguo orden simbólico contra la «moderninad» republicana, también debe conciliarse con las nuevas exigencias politicas, sociales y económicas ${ }^{4}$.

histórica de la Sección Femenina de Falange (1934-1974), Murcia, Universidad de Murcia, 2005 y Carme MOLINERO, «Mujer, franquismo, fascismo. La clausura forzada de un mundo pequeño», Historia Social, no 30, 1998, p. 97-118.

3 Michelle ZIMBALIST ROSALDO, «Mujer, cultura y sociedad: una visión teórica» en Olivia HARRIS y Kate YOUNG, Antropología y feminismo, Barcelona, Anagrama, 1979.

4 Giuliana DI FEBO, «Nuevo Estado, nacionalcatolicismo y género» en Gloria NIELFA CRISTÓBAL, (ed), Mujeres y hombres en la España franquista: sociedad, economía, política, cultura, Madrid, Instituto de Investigaciones Feministas, UCM, 2003, p. 31. 
En este sentido, tenemos que tener en cuenta que los discursos no son elementos aislados e independientes, sino que se yuxtaponen y conviven, con el objetivo de crear un proyecto de poder. El proyecto franquista se sustentaba en el establecimiento del orden tradicional, es decir, contrario al orden republicano. Así, la presencia de la mujer en la esfera pública durante la II República se sustituyó por la vuelta al hogar defendida por la tradición católica y el fascismo. El fascismo demonizó la emancipación femenina y la liberación de la mujer, mostrando un rechazo a la ruptura del sistema patriarcal, de forma que según Pilar Primo de Rivera «el deber de las mujeres para con la patria es formar familias».

El conservadurismo autoritario, el fascismo, junto con las opciones que integraron la extrema derecha concibieron un discurso común de domesticidad que perduró durante el franquismo ${ }^{6}$. La subordinación y la represión que sufrieron las mujeres durante la dictadura franquista, y especialmente durante la primera etapa del régimen responden a algo más que una vuelta atrás a la tradición. La feminidad se identifica con la fragilidad, sumisión y espíritu de sacrificio, características que enlazan perfectamente con el mensaje católico, pero además «el fascismo femenino dará a la mujer lo que necesita: custodia de la casa y de los afectos, incitadora de obras nobles, consoladora en el dolor, madre de nuestros hijos» ${ }^{7}$. Sin embargo, según Roca i Girona la mujer ideal fue el resultado del modelo burgués de ama de casa y el modelo cristianocatólico de género ${ }^{8}$. El modelo burgués se basaba en la diferenciación de la esfera productiva, centrada en el ámbito público y el trabajo, y la esfera reproductiva, centrada en el ámbito privado y el hogar. El modelo cristianocatólico se basa en el origen del Génesis y el pecado original, y pone de manifiesto dos modelos de mujer representados por la Virgen María y Eva, que encarnan la mujer austera, ángel del hogar y sumisa, por un lado, frente a la mujer libre y desobediente que seduce a los hombres, por otro lado?.

5 Pilar PRIMO DE RIVERA, Discursos, Barcelona, Editorial Nacional, 1939.

6 Rebeca ARCE PINEDO, «De la mujer social, a la mujer azul», Ayer, nº 57, 2005, p. $247-$ 272; Teresa Ma ORTEGA LÓPEZ, «Conservadurismo, catolicismo y antifeminismo: la mujer en los discursos del autoritarismo y el fascismo (1914-1936)», Ayer, no 71, 2008, p. 53-83.

7 Citado por Carme MOLINERO, «Mujer, franquismo, fascismo. La clausura forzada en un mundo pequeño», Historia Social, no 30, 1998, p. 99.

8 Jordi ROCA I GIRONA, «Fuentes y metodología para un análisis antropológico de la construcción de género en la postguerra española», en Actas del I Encuentro de Investigadores del Franquismo, Barcelona, 1992.

9 Aurora MORCILLO, «Shaping trae catholic womanhood: francoist educational discourse 
Los regímenes fascistas consideraron una cuestión primordial la vuelta de la mujer al ámbito tradicional doméstico y la maternidad ${ }^{10}$. En Italia el discurso elaborado por el fascismo otorgaba a la mujer un papel protagonista, pero siempre en el seno de la familia, como esposa y madre, como garantía de su unidad, y al mismo tiempo de la nación ${ }^{11}$. Igualmente, en Alemania el nazismo ubicó a la mujer en el hogar. Sin embargo, su diferencia con otros fascismos viene marcada por su perfeccionamiento y mejora de la raza, haciendo del cuerpo de la mujer una cuestión política y pública. El cuerpo se convirtió en un símbolo de la fortaleza nacional, donde solo una mujer sana, fuerte y limpia podía mejorar la raza ${ }^{12}$. Igualmente, el proyecto político-ideológico del régimen franquista aspiraba a controlar todos los aspectos de la vida social y en especial las relaciones que se consideraban la primera entidad natural: la familia ${ }^{13}$. La familia se convertía así en la célula principal de la sociedad, la «primera sociedad» según José Antonio Primo de Rivera. Por ese motivo había que protegerla de todo aquello que podía desestabilizarla. El Estado franquista desplegó toda una serie de mecanismos legales para reforzar la familia patriarcal con dos objetivos básicos: incrementar la natalidad y excluir a la mujer del mercado laboral. Para cumplir estos objetivos el nuevo régimen utilizó diferentes mecanismos.

El primero se basó en la ideología de la doctrina católica que avala el papel diferenciado de cada sexo en la sociedad, favoreciendo la estructura patriarcal. Así se recupera el discurso bíblico de sometimiento de la mujer según el Génesis, extendiendo la idea de la mujer que aúna fuerza y fragilidad, sensibilidad, astucia, pureza y tentación, de forma que «cuando Dios quiso

on women», en Victoria Lorée ENDERS y Pamela Beth RADCLIFF (coord.), Constructing Spanish womanhood: female identily in modern Spain, New York, State University of New York Press, 1999 , p. 57.

10 Robert O. PAXTON, Anatomía del fascismo, Barcelona, Península, 2005; Roberto Bein WILHELM REICH, Psicología del masas del fascismo, Barcelona, Bruguera, 1981; Carlota CORONADO, «Esposa y madre ejemplar: la maternidad en los noticiarios Luce durante el fascismo (1928-1945)», Historia y Comunicación Social, no 13, 2008, p. 5-31.

11 Victoria DE GRAZIA, «Patriarcado fascista: las italianas bajo el gobierno de Mussolini, 1922- 1942», en Georges DUBY y Michelle PERROT, Historia de las mijeres, El siglo XX, vol. 5, Madrid, Taurus, 1993, p. 139-170; Perry R. WILLSON, «Women in fascista Italy», en Richard BESSEL (ed.), Fascist Italy and Nazi Germany. Comparisons and contrats, Cambridge, Cambridge University Press, 1998, p. 78-93.

12 Michael BURLEIG y Wolfgang WIPPERMANN, The Radical State. Germany, 1933-1945, Cambridge, Cambridge University Press, 2006, p. 249-254; James STEPHENSON, Woman in Naz̧i Germany, Nueva Cork, Longman`s, 2001.

13 Carme MOLINERO, «Silencio e invisibilidad: la mujer durante el primer franquista» en Revista de Occidente, no 223, 1999, p. 63-85. 
sancionar el pecado original impuso a la mujer un doble castigo: el dolor en su maternidad y la sujeción al varón, que la dominarías ${ }^{14}$.

El segundo se centró en la consolidación y el apoyo incondicional desde el estado a Sección Femenina, que creó un modelo de mujer propugnado por el programa social fascista. Bajo el lema «mujeres para Dios, para la Patria y para el hogar» construyó un ideal femenino en torno a la esposa cristiana, decente, obediente, patriótica, sumisa, entregada a sus hijos y cuya virtud era el silencio ${ }^{15}$. Así, Isabel de Castilla y Teresa de Jesús se convirtieron en dos ejemplos a seguir. La primera como modelo de esposa y madre ejemplar y la segunda como símbolo de obediencia y trabajo silencioso. Esa idea se refleja en revistas propias de Sección Femenina, como Medina que señala que:

la vida de toda mujer, a pesar de cuanto ella quiera simular -o disimularno es más que un eterno deseo de encontrar alguien a quien someterse. La dependencia voluntaria, la ofrenda de todos los minutos, de todos los deseos y las ilusiones, es el estado más hermoso, por que es la absorción de todos los malos gérmenes - vanidad, egoísmo, frivolidad-por el amor ${ }^{16}$.

Pero al mismo tiempo, Sección Femenina se propuso modernizar el modelo de mujer a partir de la adquisición de conocimientos técnicos que le ayudaran a mejorar su papel como eje fundamental del núcleo familiar, alimentándose de los proyectos italianos y alemanes. Así, la Falange bajo la influencia católica, la derecha, y el fascismo europeo enmascaró su misoginia con imágenes de felicidad que exaltaban a la mujer y su papel en la sociedad ${ }^{17}$.

Junto a lo anterior, desde el campo de la medicina, biología, psicología y el psicoanálisis... se legitimaba la diferencia entre los géneros, situando

14 En Giuliana DI FEBO, «Nuevo Estado, nacionalcatolicismo y género», en Gloria NIELFA, (ed.), Mujeres y hombres en la España franquista, sociedad, economía, política y cultura, Madrid, Instituto de Investigaciones Feministas-UCM, 2003, p. 31.

15 Giuliana DI FEBO, «La Cuna, la Cruz y la Bandera. Primer franquismo y modelos de género», en Isabel MORANT DEUSA (dir.), Historia de las mujeres en España y América Latina IV. Del siglo XX a los umbrales del XXI, Madrid, Cátedra, 2006, p. 217-238.

16 Medina, 13 de agosto de 1944.

17 En este sentido véase Carme MOLINERO, «Mujer, Franquismo, Fascismo»... op. cit., p. 97-117; Rosario SÁNCHEZ LÓPEZ, Mujer española. Una sombra del destino en lo universal. Trayectoria histórica de Sección Femenina de Falange (1934-1977), Murcia, Secretariado de Publicaciones Universidad de Málaga, Málaga, 1990; Sofía RODRÍGUEZ LÓPEZ, Elpatio de la cárcel. La Sección Femenina de FET-JONA en Almería (1937-1977), Centro de Estudios Andaluces, Sevilla, 2010; Ma Teresa GALLEGO MENDEZ, Mujer, Falange y Franquismo, Madrid, Taurus, 1983. 
a la mujer en una posición inferior y subalterna ${ }^{18}$. El discurso de la medicina completaba el ideal de la maternidad limitando la feminidad a la reproducción. Discurso iniciado por la derecha durante la Restauración y la dictadura de Primo de Rivera que se ocupará de desviar el discurso feminista moderado hacia el discurso higienista, que conlleva una «diferencia psíquica» aunque no «la inferioridad mental» ${ }^{19}$. Así, debido a que biológicamente está destinada a ser madre, su psicología está determinada por este motivo, por lo que su actividad profesional debe ser entendida como una prolongación de su vocación maternal ${ }^{20}$.

Así pues, estos discursos se legitiman entre sí y son tendentes a aprobar un proyecto común apoyado por un marco legislativo concreto, estableciéndose un ordenamiento jurídico en el que la capacidad jurídica de las mujeres se encontraba sujeta al varón. Durante la Guerra Civil, el bando nacional comenzó a configurar su modelo de mujer. Dos meses después del levantamiento del 18 de julio se suprimió la educación mixta, y en 1938 se libera a la mujer casada del taller y del trabajo, apartándola no sólo de una fuente importante de ingreso para la economía familiar, sino también de una estrategia de socialización y movilidad social ${ }^{21}$. La mujer quedó reducida al ámbito doméstico mediante una legislación patriarcal y sexista. Así, el Fuero de los Españoles «reconoce a la familia como célula primaria, natural y fundamento de la sociedad, y al mismo tiempo como una institución moral dotada del derecho inalienable y superior a toda ley positivar ${ }^{22}$.

18 Sobre el discurso antifeminista de la ciencia véase: Geraldine M. SCANLON, La polémica feminista en la España contemporánea (1868-1974), Madrid, Akal, 1986, p. 161-194. Para la evolución del discurso científico y su consecuencia en España destaca Nerea ARESTI ESTEBAN, «Pensamiento científico y género en el primer tercio del siglo XX», Vasconia, $\mathrm{n}^{\circ} 25,1998$, p. $53-72$.

19 Teresa Ma ORTEGA LÓPEZ, «Conservadurismo, catolicismo y antifeminismo: la mujer en los discursos del autoritarismo y el fascismo (1924-1936), Ayer, $\mathrm{n}^{\circ}$ 71, 2008, p. 173 206; de la misma autora «Culturas liberales y catolicismo en la génesis del antifeminismo franquista», Historia Social, no 67, 2010, p. 155-171.

20 Marie A. BARRACHINA, «Discurso médico y modelos de género, pequeña bistoria de una vuelta atrás», en Gloria NIELFA, Mujeres y hombres.... op. cit., p. 70.

$21 \mathrm{M}^{\mathrm{a}}$ Carmen GARCÍA NIETO, «Trabajo y oposición popular de las mujeres durante la dictadura franquista» en Michelle PERROT y Georges DUBY, Historia de las mijeres. El siglo XX, Madrid, Taurus, 2003, p. 723.

22 FUERO DE LOS ESPAÑOLES, Título XIII, 3. 


\section{El campo de acción de Sección Femenina}

Los distintos componentes ideológicos del franquismo fueron asumidos por las organizaciones femeninas encargadas de reproducir el modelo establecido. En un mundo dominado por hombres que van a ser partícipes de la vida política del país, Sección Femenina, va a tener la misión de consolidar los roles asignados a la mujer. Sección Femenina nace al amparo de la organización masculina de Falange en 1934 con una función asistencial y de ayuda. La delegación giennense es uno de los casos cuyo origen se sitúa momentos previos a la Guerra Civil. Esta primera organización contó con 6 fundadoras y un pequeños número de afiliadas en la capital. En total 19 mujeres comenzaron a trabajar en la confección de camisas azules e insignias para los militantes falangistas, venta de sellos, reparto de propaganda, asistencia a mítines y visitas a presos, así como la organización del Socorro Blanco ${ }^{23}$. Poco a poco la organización se fue extendiendo por la zona nacional por municipios como Alcalá la Real, Porcuna y Lopera donde se organizaron los comedores de Auxilio Social.

Cuando concluye la Guerra Civil Española es el momento en el que Sección Femenina asume su tarea principal: preparar a la mujer para la construcción del nuevo Estado nacional-sindicalista. Para ello se va realizar un extenso programa social que incluye desde la creación de un cuerpo de enfermeras sociales, cuyo fin sería conocer tanto las deficiencias sanitarias como morales de las familias y proponer los remedios adecuados; hasta la promoción de la mujer campesina a partir de diferentes mecanismos; pasando por la formación de las afiliadas y no afiliadas en centros educativos ${ }^{24}$. El grado de participación en todos los ámbitos de Sección Femenina no fue el mismo en todas las provincias, aunque los departamentos de la organización eran los mismos, las actividades que se llevaron a cabo dependieron de las posibilidades económicas de cada delegación provincial, por lo que fue básica la ayuda del resto de autoridades provinciales y locales. En la provincia de Jaén, tras la finalización de la Guerra Civil se organizó formalmente Sección Femenina y Auxilio Social con comedores y cocinas de Hermandad, contado la organización con 429 afiliadas en $1939^{25}$.

23 ARCHIVO HISTÓRICO PROVINCIAL DE JAÉN (AHPJ), Fondo Sección Femenina, Expedientes de la labor realizada por Sección Femenina durante los años 1939-1976, Leg. 9491.

24 Luis SUÁREZ FERNÁNDEZ (dir.), Crónica de la Sección Femenina y su tiempo, Madrid, Nueva Andadura, 1993, p. 94-96; Adolfo MAÍLLO, Educación y revolución. Los fundamentos de una educación nacional, Madrid, Editorial Nacional, 1943.

25 AHPJ, Fondo Sección Femenina, Expedientes de la labor realizada por Sección Femenina 
Junto a la labor realizada en los centros de enseñanza, Sección Femenina influyó en la educación de las niñas a partir de sus propias escuelas ${ }^{26}$. Así, destacaron las escuelas de formación, las de hogar y las mixtas ${ }^{27}$. La diferencia radicaba en el nivel de formación de las alumnas. Aquellas mujeres que no sabían leer ni escribir asistirían a las escuelas de formación -orientadas principalmente a las mujeres de ámbitos rurales-, mientras que aquellas que tenían unos conocimientos mínimos asistirían a las escuelas de hogar, mientras que las mixtas impartirían ambas enseñanzas. Sin embargo, en la práctica tal división no existía de forma clara, ya que tuvieron generalmente un desarrollo paralelo, adoptando actividades tanto de formación como de hogar. Fue una de las apuestas más decididas de Sección Femenina para formar a la mujer en su misión principal: el cuidado del hogar. Se impartían conocimientos de puericultura e higiene, corte y confección, economía doméstica, además de las nociones básicas de política y educación física.

A lo largo de la década de los cincuenta Sección Femenina había lanzado sus redes hasta el punto de que sus centros educativos formaron parte de las dotaciones generales. Estas escuelas tuvieron una excelente acogida en Jaén tanto en la capital como en el resto de la provincia, aunque las mujeres de los ámbitos rurales se mostraron más reticentes a participar en cursos que no estuvieran directamente relacionados con su vida cotidiana. Entre 1950 y 1960 los resultados fueron espectaculares, destacando 1951 y 1952 donde llegaron a realizar estos cursos unas 900 alumnas $^{28}$.

durante los años 1939-1976, Leg. 9491.

26 Veáse sobre la educación de las mujeres Pilar BALLARÍN, La educación de las mujeres en la España contemporánea (siglos XIX y XX), Madrid, Síntesis, 2001; Mª Carmen AGULLÓ, La educación de la mujer durante el franquismo y su evolución en Valencia (1951-1970), Valencia, Universitat de València, 1994; Carlos DE PABLO, «La depuración de la educación española durante el franquismo (1936-1975): institucionalización de una represión», Foro de educación, $\mathrm{n}^{\circ}$ 9, 2007, p. 203-228; Juan Carlos MANRIQUE, «La educación física femenina y el ideal de mujer en la etapa franquista», Revista Internacional de Medicina y Ciencias de la Actividad Física $y$ del Deporte, $\mathrm{n}^{\circ} 10,2003$, p. 83-100; Francisco MORENTE, «Los fascismos europeos y la política educativa del franquismo», Historia de la educación: Revista interuniversitaria, $\mathrm{n}^{\circ} 24$, 2007, p. 179-204; Antonio F. CANALES SERRANO, «La paradoja de la educación en las mujeres bajo el franquismo», IV Encuentro de investigadores sobre el franquismo. Zaragoza, 2006, p. 680-693; Teresa GONZÁLEZ, «Los programas escolares y la transmisión de roles en el franquismo: la educación para la maternidad», Bordón. Revista de Pedagogía, no 61/3, 2009, p. 93-106.

27 Idem, p. 105-111.

28 AHPJ, Fondo Sección Femenina, Expediente de la labor realizada por la Delegación provincial de Sección Femenina, años 1939-1970 «Labor realizada durante diez años por la delegación provincial de la Sección Femenina de FET y de la JONS», Leg. 9522. 
Las actividades dirigidas a mandos y consejos provinciales en los que se desarrollaban los conocimientos que deberían transmitir a sus afiliadas y a la sociedad en general se impartían a través de lecciones de ortografía, puericultura, aritmética, funcionamiento de personal, funcionamiento de la Hermandad, organización de sindicatos, de talleres, Historia Sagrada, Historia de España, nacionalsindicalismo, religión... Para las afiliadas se desarrolló todo un programa de cursos cuyo objetivo era especializarlas en alguno de los campos en los que trabajaba Sección Femenina. En este sentido, se organizaron en Jaén cursos de enfermeras, de educación física, de vendimia, de taquigrafía, de divulgadoras rurales, visitadoras, de instructoras de hogar, etc. En el ámbito juvenil una de las actividades que más apoyo tuvo y en la que se invirtió más dinero fueron los albergues de verano. El más importante en la provincia fue el albergue juvenil de La Yedra, que abría sus puertas en periodo estival y que ofrecía a sus alumnas toda una serie de actividades con el objetivo de encuadrar a las mujeres en los principios del régimen ${ }^{29}$.

Junto a la actividad formativa, no podemos dejar de lado la destacada labor asistencial, como una continuación de las actividades desarrolladas por la Sección Femenina desde su etapa de nacimiento. Aquí destaca la labor realizada por el Departamento de Divulgación, que a partir de la misión de las visitadoras en las zonas urbanas y de las divulgadoras sanitarias-rurales en las zonas más apartadas, desarrollaron diversas campañas a favor del cuidado infantil, trabajando en el campo sanitario, reparto de víveres (en especial leche y harina en polvo para los niños más necesitados), la confección de cestitas para bebés y las campañas de higiene. Para ello llevaron a cabo un riguroso control asistencial mediante elaborados ficheros y cuestionarios. Junto al beneficio que podía obtener la población, estas visitas permitían ejercer un control directo sobre las familias, actuando de forma eficaz sobre las capas sociales más desfavorecidas. Estas campañas llegaron a suponer una fórmula brillante de adoctrinamiento, insistiendo en aquellas cuestiones que mayor poder de convicción tenían entre la población con bajos recursos ${ }^{30}$. La labor tanto de las visitadoras como de las divulgadoras rurales y las instructoras de los Hogares Rurales y las Cátedras Ambulantes a parte de la asistencial y la formación político social fue la de conectar con

29 Idem.

30 Para la labor de divulgadoras y visitadoras véase Inmaculada BLASCO HERRANZ, Armas femeninas para la contrarrevolución: La Sección Femenina en Aragón (1936-1950), Málaga, Atenea/ Universidad de Málaga, 1999, p. 117. 
las clases populares. Rosario Sánchez indica que establecieron un puente entre las gentes más humildes y el Estado, provocando una adscripción al régimen basada más en el agradecimiento emotivo que en el conocimiento de la realidad política ${ }^{31}$. El papel de las instructoras rurales era a menudo ensalzado en la prensa debido a su importante laboral social, señalando que «ser instructora rural es poseer una profesión atractiva y amena que ofrece estímulos de todo tipo y encauza perfectamente cualquier inquietud de la mujer de hoys ${ }^{32}$.

La exaltación del mundo rural por el franquismo para evitar que los pueblos se despoblaran es apoyada por la labor de Sección Femenina dirigida a divulgar la idealización de la vida en el campo y la participación de la mujer en los trabajos agrícolas con una clara orientación profesional. En provincias como Jaén donde la agricultura era el sector principal de la economía y donde la sangría de la emigración iba despoblando las zonas rurales, Sección Femenina trató de remediar el problema de la escasa formación profesional de las mujeres y la inexistencia de expectativas de futuro. Dentro de este plan dirigido a mejorar las condiciones de vida en el campo a partir de la capacitación profesional de las mujeres campesinas a través de Instructoras Rurales, Sección Femenina estableció una red de centros y actividades donde pudieron extender su labor divulgadora y formativa. Estos objetivos se plasmaron en el desarrollo principalmente de Cátedras Ambulantes y Hogares Rurales de Colonización.

Las Cátedras Ambulantes fueron creadas y organizadas por Sección Femenina durante el régimen franquista para formar y asistir a la población rural durante uno o dos meses aproximadamente. A pesar de que la labor formativa de Sección Femenina comenzó durante la Guerra Civil su alcance no llegó a toda la geografía española, de forma que se puso en funcionamiento el servicio de las Cátedras Ambulantes con el objetivo de «llegar a las mujeres de las zonas rurales y asi incorporarlas al momento actual de la vida españolar ${ }^{33}$. Las Cátedras Ambulantes eran centros móviles de promoción y desarrollo que a través de su recorrido por el medio rural intentaban llevar a los pueblos los medios necesarios para su desarrollo y mejora de las condiciones de vida de

31 Rosario SÁNCHEZ LÓPEZ «Trayectoria histórica de la Sección Femenina de Falange (1934-1977)», en Ramón JIMÉNEZ MADRID (coord.), Mirando al mar, vol. 4, 2008, p. 209. 32 Jaén, 15 de septiembre de 1973, p. 10.

33 SECCIÓN FEMENINA, Cátedras de la Sección Femenina: Organización, SF de la FET y de las JONS, Madrid, p. 4. 
sus habitantes ${ }^{34}$. Sin embargo, a pesar de querer mejorar la situación de las zonas más remotas no se puede dejar de lado la intención propagandística de los principios ideológicos de la Sección Femenina. La exaltación y revalorización de la vida rural y del campo también quedó manifiesta con la creación de las Cátedras Ambulantes a través de las enseñanzas prácticas aplicadas al medio rural. Igualmente, la utilización de la mujer como instrumento de cambio de la sociedad y responsable de transmitir los valores tradicionales sobre la familia fue un elemento básico de las Cátedras, ya que los cursos iban dirigidos especialmente a las mujeres.

En 1946 se crea la primera Cátedra Ambulante Nacional llamada «Francisco Franco». Desempeñó su función por los pueblos de Guadalajara, Ávila, Teruel y las zonas más incomunicadas y pobres de Segovia, Albacete, Cuenca y Ciudad Real. A partir de 1954 y hasta 1958 fueron surgiendo los Equipos de Cátedras provinciales a partir del éxito que consiguieron con su labor. En Andalucía se constituyeron un total de catorce Cátedras, inaugurándose la de Jaén en 1955, llegando incluso a tener en la provincia en alguna ocasión dos Cátedras itinerantes: «Francisco Franco» y «Francisco Rodríguez Acosta». Las Cátedras Ambulantes en la provincia de Jaén permanecieron hasta 1976 visitando un total de 142 pueblos, recibiendo formación un total de 191.200 personas $^{35}$.

La acción formativa de las Cátedras iba dirigida a las mujeres puesto que su situación en el mundo rural era bastante precaria. En este sentido, desde Sección Femenina se alude a que:

nadie ignora en qué condiciones vive la mujer en los pueblos; su trabajo es agotador; no sólo cuida del marido y de los hijos; atiende la casa, los animales, acarrea el agua, sino que también ayuda al hombre en muchas ocasiones en las faenas agricolas, y lo más grave es que todas estas labores las realiza con una falta total de comodidades domésticas ${ }^{36}$.

Sin embargo, con el tiempo se vio necesario la extensión a todo el medio rural, de forma que era necesaria su aplicación tanto a los hombres como

34 SECCIÓN FEMENINA, Cátedras de la Sección Femenina. Organización, Madrid, industrias gráficas Magerit, 1965, p. 4.

35 AHPJ, Fondo Sección Femenina, Expedientes de la labor realizada por la Delegación provincial de la Sección Femenina. 1939-1970, Leg. 9522.

36 SECCIÓN FEMENINA, Organización, Madrid, Industrias gráficas Magerit, 1965, p. 36. 
a los niños. En Jaén, desde el primer momento las Cátedras estuvieron dirigidas a «todos los habitantes sea cual fuere su edad, sexo y condición ${ }^{37}$. En este sentido la Delegación Nacional de la Sección Femenina lo justificaba de la siguiente forma:

en un principio la Cátedra se pensó dirigida exclusivamente a la mujer; el programa era ambicioso: alfabetización, lucha contra la mortalidad infantil, campañas de higiene y divulgación sanitario-social, formación para el hogar, preparación para una mejor explotación de los propios recursos [...] Muy pronto los hombres empezaron también a interesarse en una serie de enseñanzas tales como, por ejemplo, el curtido y aprovechamiento de pieles, las posibilidades de explotación de los animales domésticos, la técnica de elaboración de determinados productos... ${ }^{38}$

El equipo de las Cátedras Ambulantes estaba compuesto por una jefa de cátedra, responsable del Plan Social y de las clases de formación políticosocial; una enfermera o divulgadora, encargada de extender las enseñanzas de puericultura, higiene y medicina casera; una instructora rural, encargada de las enseñanzas prácticas aplicadas al medio rural; dos profesoras de hogar, responsables de corte, confección y economía doméstica; una profesora de labores y trabajos manuales; y una instructora de juventudes.

Los pueblos a los que iban destinados la misión de las Cátedras fueron, por tanto, pequeñas poblaciones atrasadas donde se acentuaba toda clase de problemas debido a su ubicación rural, generalmente más descuidadas por las instituciones. Puesto que muchos de los municipios de Jaén contaban con estas premisas era necesario realizar una selección, ya que no todos podían resultar ser beneficiarios, debido a limitaciones de tiempo y al número de Cátedras. Para la elección de los pueblos destinatarios, cada provincia contaba con un mapa dividido en zonas teniendo en cuenta la similitud de las características de los pueblos (industriales, geográficas, comunicaciones...).

Normalmente, lo primero que detectaban las Cátedras cuando llegaban a cualquier localidad era la falta de higiene entre las niñas «como iban la mayoría sin peinar, empezamos exigiéndoles fuesen peinadas y lavadas y esto parece ser que retiró

37 AHPJ, Fondo Sección Femenina, Labor realizada durante diez años por la delegación provincial de la Sección Femenina de la FET y de las JONS. Jaén, Leg. 9522.

38 DELEGACIÓN NACIONALDELA SECCIÓN FEMENINA DEL MOVIMIENTO, Cátedras Ambulantes «Francisco Franco», Madrid, Almena, 1970, p. 1-2. 
a bastantes ${ }^{39}$. Por ejemplo, en Jódar, las condiciones de vida de la población eran lamentables, sobre todo de las personas que vivían en las cuevas tal y como se indica en las siguientes líneas:

lo que nos preguntaban era que si llevábamos algo para darle, importándose mucho las medicinas. La mayoría nos llamaban desde sus cuevas para que viéramos algún enfermo y les explicábamos una vezy otra que ya subiríamos en días sucesivos a visitar cueva por cueva, como asi se bizo $0^{40}$.

En cuanto a la forma de llevar a cabo la alfabetización tenemos que tener en cuenta diferentes opiniones. Por un lado Luis Suárez indica que «llevaban un método de alfabetización rápido, logrando en el tiempo de permanencia de la Cátedra magníficos resultados $\rangle^{41}$. Sin embargo, esta visión positiva contrasta con el testimonio de aquellos que participaron y desarrollaron la labor formativa, señalando que las enseñanzas debían adaptarse a las características particulares del pueblo. El programa curricular básico sólo tenía un carácter orientativo y no debía seguirse «al pie de la letra sin ninguna adaptación ${ }^{42}$. Como ejemplo podemos recoger unas líneas de la memoria llevada a cabo por la Cátedra Ambulante de Jódar donde se indica que:

clases de lectura y escritura no pensábamos tener, porque en un mes no da tiempo para nada, pero unas muchachas que iban al curso de las cuevas, como nosotras las llamábamos nos lo pidieron y accedimos ${ }^{43}$.

Por otro lado, junto a las Cátedras Ambulantes otras actividades que tuvieron una gran repercusión fueron las que se desarrollaron en los Hogares Rurales. Tenían un carácter formativo permanente y fueron organizados en el medio rural para elevar el nivel de vida de los pueblos. Al hilo discursivo de los principios de Sección Femenina estos centros pretendían conseguir:

la trascendental misión de la mujer en la familia y la decisiva influencia que ejercen sobre los pueblos, todo lo que con ella se haga tendrá una inmediata repercusión moral, cultural, social y económica en la sociedad ${ }^{14}$.

39 Idem.

40 Idem.

41 Luis SUÁREZ FERNÁNDEZ, Crónica de la Sección Femenina... op. cit., p. 142. 42 SECCIÓN FEMENINA, Programas, Madrid, 1965, p. 16.

43 AHPJ, Fondo Sección Femenina, Informe de la Cátedra Ambulante de Jódar, Leg. 9481.

44 REGIDURÍA DE TRABAJO, Hogares rurales de la Sección Femenina. Organizacióny funciones, Madrid, Artes Gráficas Ibarra, 1962, p. 2. 
Los Hogares Rurales de Colonización desarrollaron todo un plan de tipo formativo y recreativo dirigido a mujeres y niñas a realizar en el trascurso del año en horarios compatibles con la jornada escolar. Su plan de actuación pretendía seguir la labor iniciada de las Cátedras Ambulantes, con un carácter permanente y continuo con el objetivo de que no cayera en el olvido las actividades iniciadas en las Cátedras.

Los objetivos de planes de actividades de los hogares rurales fueron que las mujeres se integraron como miembros activos de los mismos, proyectándose sobre todo el pueblo y realizando en común los planes y actividades encaminadas a una completa preparación de la mujer en su triple aspecto de vida: como mujer, hija y esposa o madre; como directora y administradora del hogar y de los bienes espirituales y domésticos del mismos; y como trabajadora colaborando y participando con el hombre en el trabajo agrícola. Sección Femenina trató de ayudar a la mujer campesina a rentabilizar sus recursos en los trabajos agrícolas a partir de la formación y capacitación en nuevas técnicas. Así, a pesar de estimular valores como la colectividad y el interés por aumentar el nivel cultural, social, económico... y la participación de la mujer en la empresa agrícola, en la vida municipal y sindical de los pueblos, esto no debe desviar la atención sobre el papel encomendado a la mujer, hecho que no se olvidaría gracias a los cursos y charlas que tenían lugar en estos centros, que le recordarían cuál es su puesto y responsabilidad dentro de la sociedad franquista.

Las Instructoras Rurales llevaban a cabo un plan de trabajo dividido en tres áreas: formativa, centrada en la orientación agrícola, la economía doméstica rural y la formación general, otra recreativa; y finalmente la dirigida a actividades complementarias, orientada a la organización de concursos, viajes, guarderías infantiles, cursos de puericultura, etc. Destacaron diferentes actividades como las campañas agrícolas manuales. Como mecanismo para fomentar el desarrollo de las industrias caseras rurales y estimular a las mujeres para mejorar sus explotaciones y crianzas caseras se convocaban anualmente coincidiendo con las fiestas de San Isidro o del Patrono del pueblo concursos-exposiciones de crianza de animales, productos de huerta y conservería y artesanía rural. También se desarrollaron campañas anuales de cuidado y embellecimiento de casas y pueblos. A parte de premios anuales en metálico se entregaban otros premios de uso práctico para los hogares. En estos concursos se premiaban: 
las casas más cuidadas, los patios y balcones más floridos, las cuadras más limpias y la mujer de aquel pueblo pendiente de ello durante el año [...] llegando a sentir la necesidad de ello para vivir mejor ${ }^{45}$.

También se desarrollaron actividades formativas y de recreo tales como coros y danzas, educación física, albergues de otoño, biblioteca, así como campañas anuales de divulgación sanitaria de cuidado de niños, limpieza, vestido y alimentación. En general la asistencia solía ser bastante numerosa y las Instructoras Rurales incidían en el gran interés mostrado por todas aquellas mujeres que asistían. En total la provincia de Jaén llegó a tener 22 Hogares Rurales distribuidos por toda la geografía, siendo después de Badajoz con 33 la provincia que contó con un mayor número de estos centros $^{46}$.

\section{La evolución del discurso de Sección Femenina a finales del FRANQUISMO}

Manuel Pérez Ledesma indica como los cambios básicos en la dirección política del franquismo influyeron tanto causas internas como externas ${ }^{47}$. Así, la evolución de la fascistización de la etapa azul a la recatolización como pilar básico del régimen posteriormente obedeció no sólo a la situación internacional después de la Segunda Guerra Mundial, sino también al agotamiento de los mandos de las falangistas después del periodo de implantación. Los últimos años del franquismo relacionados directamente con la crisis falangista y un nuevo marco legislativo encajarían en la aparición de una sociedad de consumo, que pretendía subordinar la falta de libertad política al placer del aumento del poder adquisitivo.

De forma intermitente tanto en las revistas divulgativas de Sección Femenina como en los programas radiofónicos se va aludiendo al reconocimiento paulatino del trabajo de la mujer fuera del hogar. La revista Consigna se hace eco de la transformación de la sociedad y de los cambios que ello conlleva para la mujer con las siguientes palabras:

45 AHPJ, Expediente de actividades en hogares rurales de colonización, 1960-1975, «Plan general de actividades a organizar», Leg. 9540.

46 Luis SUÁREZ FERNÁNDEZ, Crónica de la Sección Femenina... op. cit.

47 Manuel PÉREZ LEDESMA, «Una dictadura por la Gracia de Dios», Historia Social, $\mathrm{n}^{\circ}$ 20, 1994, p. 173-193. 
la complejidad de la vida moderna ha producido alteraciones muy hondas en esta posición y ha revolucionado las ideas sobre el fin y la extensión del trabajo femenino y como consecuencia la participación de la mujer en la comunidad, su libertad ${ }^{48}$.

A partir de los cincuenta la organización, influida por la entrada de una nueva generación de mujeres en la cúpula de Sección Femenina, tratará de asignarse progresivamente un nuevo papel. De este modo, su inclinación evolucionó hasta acortar distancias con el pueblo representando los intereses de la población sobre la que pretendía actuar, esforzándose por producir cambios políticos y sociales en amplios sectores de la población femenina ${ }^{49}$. Sería a partir de la apertura de finales de la década de los cincuenta y a raíz de la promulgación de la Ley de Derechos Políticos, Profesionales y de Trabajo de la Mujer ${ }^{50}$ en 1961 cuando Sección Femenina intente aparentemente arroparse con la vestidura pseudo-feminista, inclinándose de forma más decidida por la introducción de la mujer en el mercado laboral y extendiendo su nueva oferta de ocio al amparo de la nueva ley de asociaciones, frente al periodo anterior marcado por el carácter asistencial y benéfico. Precisamente se produciría el ingreso de las mujeres no sólo en el trabajo doméstico, la industria ligera y textil, sino también en la administración y servicios. En este sentido, Geraldine Scanlon indica que a lo largo de los últimos años, Sección Femenina se encargó de fomentar los derechos de la mujer y trató de eliminar su incómodo pasado antifeminista ${ }^{51}$. A pesar del escepticismo inicial, el papel de Sección Femenina fue el catalizador de los cambios a partir de 1961, ayudando a una mayor permisividad de la vida cotidiana.

Un cambio en la sociedad española consecuencia no sólo de que las mujeres se hubieran incorporando poco a poco al mercado laboral, sino también de las transformaciones económicas que se estaban produciendo

48 Consigna, febrero 1970.

49 Inbal OFEL, «La legislación de género de la Sección Femenina de la FET. Acortando distancias entre la política de élite y la de masas», Historia y política: ideas, procesos y movimientos sociales, $\mathrm{n}^{\circ} 15,2006$, p. 236 y ss.

50 Véase $\mathrm{M}^{\mathrm{a}}$ del Rosario RUIZ FRANCO, «Nuevos horizontes para las mujeres de los años 60: la ley de 22 de junio de 1961», Arenal. Revista de Historia de las Mujeres, no 2/2, 1995 p. 247-268; Sofía RODRÍGUEZ LÓPEZ, «La Sección Femenina de FET-JONS: «paños calientes» para una dictadura», Arenal. Revista de Historia de las Mujeres no 12/1, 2005, p. 35 60; Cristina GÓMEZ CUESTA, «Entre la flecha y el altar: el adoctrinamiento femenino del franquismo. Valladolid como modelo, 1939-1959», Cuadernos de Historia Contemporánea, $\mathrm{n}^{\mathrm{o}} 31,2009$, p. 297-317.

51 Geraldine SCANLON, «La mujer bajo el franquismo», Tiempo de Historia, no 7, p. 5-28. 
en el país y que hacían preveer la necesidad de mano de obra. Una mano de obra que vendría del grueso de mujeres que se encontraban económicamente inactivas y que constituían una importante fuerza de trabajo. De este modo, aparentemente se consagraba la igualdad jurídica de las mujeres en las actividades políticas, profesionales y laborales. Esta Ley fue adoptada por el gobierno a partir de una proposición elaborada por la Sección Femenina de la Falange señalando que no se trataba de una ley igualitaria, sino más bien lo contrario:

...queremos hacer del hombre y la mujer dos seres iguales; ni por naturaleza ni por fines a cumplir en la vida podrán nunca igualarse, pero si pedimos que, en igualdad de funciones, tengan igualdad de derechos... La Ley en vez de serfeminista es, por el contrario, el apoyo que los varones otorgan a la mujer, como vaso más flaco, para facilitarle la vida (una mujer culta, refinada y sensible, por esa misma cultura es mucho mejor educadora de sus hijos y más compañera de su marido) $)^{52}$.

No cabe duda de que Sección Femenina impulsó la visibilidad de las mujeres en el ámbito social y público, intentando mejorar las posibilidades profesionales y frenar la emigración, especialmente las de ámbitos rurales, ayudándolas a optimizar sus recursos en las tareas agrícolas a través de la formación y preparación en nuevos procedimientos. Sin embargo, simultáneamente, este avance en el discurso falangista no prescindía de uno de los pilares básicos al orientar a las mujeres en su papel fundamental de amas de casa, esposas y madres, cometido básico entre todas. De este modo, se presencia una serie de contradicciones entre el discurso ideológico de Sección Femenina y los cambios económicos producidos en la década de los años sesenta, donde se produce la transformación de una sociedad rural y tradicional en una sociedad industrial y consumidora.

La creación de la mutualidad para las trabajadoras del hogar en 1959 significó una importante apuesta y logro de Sección Femenina para profesionalizar y canalizar la incorporación de las mujeres al mundo laboral. Un seguro que beneficiaría al sector de trabajadoras más importante del país durante los años sesenta. Un servicio doméstico que se caracterizaba en la mayoría de los casos por la inexistencia de contratos de trabajo, el carácter temporal del empleo, el abuso, el maltrato generalizado o la convivencia con

52 Citado en $\mathrm{M}^{\mathrm{a}}$ del Rosario RUÍZ FRANCO, «Nuevos horizontes para las mujeres...» op. cit. , p. 264. 
los patronos, indicando la vulnerabilidad de estas mujeres ${ }^{53}$. La organización se hizo con el mérito de apoyar la causa de este destacado número de mujeres, especialmente en las ciudades, donde llegaban esas jóvenes que salían del campo sin preparación profesional. Además, solía ser el primer empleo para la mayoría de las mujeres que emigraban tanto para las casadas como para las jóvenes solteras, casi niñas, de familias pobres del medio rural que se trasladaban a la ciudad y se empleaban en las casas a cambio de comida y cama.

El papel subordinado de la mujer se oponía a los logros de realización personal que se estaban produciendo en el mercado laboral procedentes del contexto urbano. La ciudad proporcionaba un futuro más amplio de posibilidades no sólo en instrucción sino también en cualificación para el desarrollo posterior de una carrera profesional. Sin embargo, esa situación chocaba con el papel tradicional de la mujer, de forma que podía dar lugar a problemas de moralidad según denunció la delegación provincial de Sección Femenina de Jaén, ya que «al ser chicas jóvenes, sin preparación, ni experiencia en multitud de ocasiones estaban expuesta a una excesiva vulnerabilidad $\aleph^{54}$. Para las mujeres casadas el servicio doméstico por horas era el habitual, compaginándose con las tareas de su hogar y el cuidado de sus hijos. Sin embargo, la tónica general de estas mujeres que trabajaban en el servicio doméstico era la falta de seguridad social. El hecho de que el sistema general de la seguridad social que garantizaba a la mujer casada la cobertura de los beneficios sanitarios y de viudedad por la cotización del marido abandonaba el interés de la mujer por cotizar en la seguridad social tanto como autónoma como en el régimen de servicio doméstico. Sin embargo, cuando la mujer no tenía la cobertura del marido, en este caso para las viudas o las solteras en una edad avanzada procuraban por todos los medios conseguir que en la casa donde trabajaban les pagara la seguridad social. A pesar de que el trabajo de la mujer en el servicio doméstico era bastante duro, la mayoría de las mujeres procedentes de las zonas rurales asumieron el cambio con todas las consecuencias e incluso valoraron mejor el trabajo actual comparado con el que tenían en su pueblo ${ }^{55}$. En definitiva, lejos de «proteger a la mujer» el

53 José Antonio, PÉREZ Y PÉREZ, «Trabajo doméstico y economía sumergida en el Gran Bilbao a lo largo del desarrollismo, un mundo invisible y femenino», en José BABIANO (ed.), Del hogar a la buelga obrera durante el franquismo, Madrid, Catarata, 2007, p. 101-102.

54 AHPJ, Fondo Sección Femenina, Informe de la secretaría provincial del VI Congreso provincial de la Sección Femenina en Jaén, 1962, Leg. 9522.

55 AHPJ, Fondo Sección Femenina, Ponencias de las Jornadas técnicas de Promoción Profesional de 
franquismo en su última etapa siguió alimentando la actividade doméstica y el empleo sumergido.

Sin embargo, algunos de los éxitos de esta organización en lo que se refiere a la orientación profesional de las mujeres durante el desarrollismo, no consiguieron satisfacer las nuevas demandas sociales que se estaban generando en la sociedad española, encaminadas a la búsqueda de una nueva identidad femenina. Las mujeres de ámbitos rurales no tenían otra opción más que la de integrarse en la actividad agrícola de la explotación familiar. La ausencia de salidas en el mundo rural, junto con la búsqueda de una mayor autonomía, junto con el hecho de acompañar a sus familias fueron, entre otros, los motivos que provocaron una fuerte emigración femenina. Así, ante las pésimas condiciones de vida en el mundo rural la única vía posible para poder sobrevivir de muchas familias durante la década de los cuarenta, cincuenta, sesenta y setenta sería la emigración hacia los centros industriales y urbanos de la Península y Europa, destacando Andalucía por ser la comunidad que más población vio salir fuera, estando la provincia de Jaén a la cabeza de tal situación. En la década de los años sesenta se produjo precisamente un ritmo anual de más de 15.000 emigrados. Para paliar esta situación Sección Femenina apostó por la creación de cooperativas de confección industrial en algunas zonas rurales de la provincia, con el objetivo de mitigar la emigración femenina ${ }^{56}$.

De este modo, Sección Femenina estuvo marcada en las dos últimas décadas del régimen por la confusión entre la nostalgia y la apuesta más enérgica de renovarse o morir. Fueron unos años de una gran actividad de divulgadoras rurales, Hogares Rurales y Cátedras Ambulantes. Incluso empieza a ponerse en marcha un servicio de orientación profesional hacia la mujer rural a través de diversas campañas a partir de diferentes medios de difusión, informando sobre las distintas profesiones a las que la mujer del medio rural podía tener acceso ${ }^{57}$. Sección Femenina ayudó a aumentar la presencia y visibilidad de las mujeres en Jaén en el ámbito público y social de forma activa y participativa tratando de mejorar sus posibilidades en el campo profesional, ayudando especialmente a la mujer campesina a rentabilizar sus recursos en los trabajos agrícolas a partir de la formación y

la mujer en los medios rurales y suburbanos, 1974, Leg. 9487.

56 AHPJ, Fondo Sección Femenina, Estudio de la juventud rural, 1964, Leg. 9522.

57 AHPJ, Fondo Sección Femenina, Ponencias de las Jornadas técnicas de Promoción Profesional de la mujer en los medios rurales y suburbanos, 1974, Leg. 9487 
capacitación en nuevas técnicas. Su objetivo era formar profesionalmente a las mujeres de las zonas rurales y elevar su nivel de preparación en las tareas agrícolas, tratando de mejorar la explotación familiar agraria, tarea que acometió el Departamento de Hermandad de la Ciudad y Campo. Debido al peso de la sociedad rural en la provincia de Jaén, la labor realizada por las regidoras rurales que impartieron cursos sobre materias agrícolas y del hogar fue más que importante, sobre todo porque fueron muy bien valoradas entre la población. Así, Sección Femenina consciente de estas necesidades se planteó la necesidad de reformar el campo a través de la capacitación profesional de las mujeres ${ }^{58}$ para afrontar el reto de asumir las actividades agropecuarias, las industrias rurales complementarias a la economía rural, así como de la promoción de la mujer campesina para su proyección familiar y social $^{59}$. Esta campaña tuvo realmente sus efectos en la provincia, ya que en muchos pueblos y aldeas las mujeres empezaban a demandar trabajo, siendo lo más inmediato en la provincia la recogida de aceituna. En este sentido la tarea más urgente era la creación de guarderías donde las madres pudieran dejar a sus hijos.

Sin embargo, mientras luchaba por conseguir ciertos derechos para la mujer y potenciar el trabajo fuera del hogar, Sección Femenina seguía echando la vista atrás y ensalzando el papel tradicional de la mujer como esposa y madre. Para ello no sólo desplegó todo un campo de ocio alrededor de toda una serie de asociaciones, sino que también seguía desarrollando diversos cursos, dedicados especialmente a las labores tradicionales que la mujer ha desempeñado como bordado, cocina, enseñanzas de economía doméstica, puericultura, intercalados en ocasiones con otros como introducción a la mecánica del coche, o nuevos electrodomésticos dentro del contexto de una sociedad de consumo y desarrollo. En noviembre de 1967 se creó la Asociación de Amas de Casa, que organizaba cursillos dirigidos a las mujeres rurales y diferentes charlas sobre valores tradicionales, cristianos, el matrimonio, el papel de la mujer en la sociedad, etc., contando para ello con el apoyo de la iglesia. Se posicionaron a favor del modelo de educación que propugnaba la Federación Católica de la Asociaciones de Padres de Familia y Padres de Alumnos de Madrid, estando a favor de la formación trascendente y la iniciativa privada. La Asociación de Amas de Casa llegó a contar con varias delegaciones locales

58 Sara RAMOS ZAMORA y Teresa RABAZAS ROMERO, «Mujeres e instrucción rural en el desarrollismo español», Historia de la Educación, nº 26, p. 221-256.

59 REAL ACADEMIA DE LA HISTORIA, Archivo Documental de Nueva Andadura, Sección Femenina del movimiento, La instructora rural, carpeta 79 (serie azul), no A-5. 
en Alcalá la Real, Alcaudete, Arjona, Andújar, Bailén, Cazorla, Fuerte del Rey, La Carolina, Lopera, Martos, Marmolejo, Mengíbar, Porcuna y Úbeda. Posteriormente, y con la llegada de la democracia surgiría la creación de la Asociación de Mujeres Rurales a finales de 1976 en diferentes localidades, con el objetivo de ofrecer un cauce de promoción y colaboración en la solución de los problemas que afectaba a la vida de los pueblos, intentando una mayor promoción cultural de la mujer en el medio rural. En marzo de 1977 quedó constituida formalmente, contando con un millar de asociadas en toda la provincia $^{60}$.

Años donde la pugna por la supervivencia de Sección Femenina se manifiesta en su papel en los ayuntamientos, consejos locales, enlaces jurado, instructoras y promotoras de asociaciones, mezclándose con la lucha en los movimientos feministas, más en consonancia con las preocupaciones reales de la mujer. Poco a poco la organización se va a ir infiltrando en empresas promocionadas por Sección Femenina a partir de reuniones mensuales en las que se trataba los problemas habidos en las empresas. Concretamente en las elecciones sindicales de 1966 fueron elegidas 58 enlaces de Sección Femenina en la provincia en un total de 36 empresas $^{61}$. La ley 82/1968 establecía la participación de las mujeres en las corporaciones locales como concejales además de los vecinos cabeza de familia a la mujer casada, destacando su papel decisivo y sus sugerencias en la resolución de problemas locales. La llegada de los gobiernos de Arias Navarro, y especialmente el Adolfo Suárez, tras la Ley para la Reforma Política de diciembre de 1976, propiciaron la salida a la calle de la ciudadanía y la adaptación del personal del Movimiento a la democracia. Situación que daría lugar a que las mujeres de Sección Femenina trataran de entrar en la administración pública, especialmente en el campo de la cultura, educación, sindicatos o la administración del nuevo Estado democrático.

\section{Conclusión}

A través de estas páginas hemos pretendido poner de manifiesto una cuestión básica a la hora de analizar el papel de Sección Femenina durante

60 Ideal, 18 de marzo de 1977, p. 13.

61 AHPJ, Fondo Sección Femenina, Expedientes de la labor realizada por Sección Femenina durante los años 1939-1976, Anexo n VII, Leg. 9491. 
el régimen franquista: la formación y el componente de adoctrinamiento político de la mujer. Hay que destacar que cada vez son más abundantes los estudios sobre el universo femenino y su contribución al rol de la mujer en el régimen franquista. El nuevo ideal de feminidad basado en la domesticidad, la maternidad y la subordinación al hombre aprovechó la función de la mujer como pieza clave de la primera entidad natural de la sociedad: la familia, con el objetivo de asegurar la estabilidad y la recuperación nacional. Para ello hemos tomado como ejemplo una provincia andaluza, Jaén, que destaca por la preeminencia del mundo rural y donde Sección Femenina tuvo un amplio escenario de actuación. Un campo de acción cuya misión va a ser consolidar los roles asignados a la mujer a través de toda una serie de actividades y programas de formación. Junto a la labor desempeñada en los centros de enseñanza, Sección Femenina influyó en la educación de las niñas con sus propios medios a partir de las escuelas de formación, hogar y mixtas. Además, en provincias como Jaén donde el sector principal de la economía era la agricultura y la emigración a las ciudades era la tónica general, Sección Femenina trató de retener y mejorar las condiciones de vida en el campo a partir de la capacitación profesional de las mujeres. Para ello se desplegó toda una serie de Hogares Rurales y Cátedras Ambulantes, cuyo objetivo no era sólo potenciar el mundo rural, sino realizar una radiografía social y política de aquellas zonas más apartadas de la geografía nacional. En toda esta tarea, las divulgadoras y las instructoras rurales fueron un pilar básico conectando las clases populares con la labor del Estado, provocando en buena medida una adscripción al régimen basado en la gratitud y bondad de aquellas «señoritas» más que en el conocimiento de la realidad política. Labor que sin duda el régimen trató de ensalzar y reconocer.

Sin embargo, a medida que el régimen va evolucionado y se adentra en la época del desarrollismo, la sociedad de consumo y el desarrollo de un nuevo marco legislativo el discurso oficial de Sección Femenina intenta transformase y adaptarse a los nuevos tiempos que corren. Progresivamente se va aludiendo al reconocimiento del trabajo de la mujer fuera del hogar. Años que estuvieron marcados por una contradicción entre la nostalgia de tiempos pasados y la apuesta por renovarse. Sección Femenina trató de aumentar la presencia y visibilidad de las mujeres en Jaén y evitar la fuerte emigración de las zonas rurales, ayudándoles a rentabilizar sus recursos en los trabajos agrícolas a través de la formación y capacitación de nuevas actividades. Igualmente, la apuesta por la mutualidad de las trabajadoras del hogar, buena parte de ellas procedentes de las zonas rurales del país, y 
su participación cada vez más importante en el ámbito público y político a través de enlaces jurado en empresas, ayuntamientos y consejos locales, convive con su trabajo en la esfera de ocio, organizando toda una serie de asociaciones y cursos para la mujer cuyo objetivo seguía siendo resaltar el papel de la mujer dentro del hogar. 